\title{
5. Signs and Wonders: The uncanny verum and the anthropological illusion
}

\author{
Kevin Birth
}

As a Caribbeanist studying under Donald Tuzin, I was struck by the ways in which Don could make the implications of his ethnographic work relevant to my struggles with material from Trinidad. Often this involved delving into the ontological and epistemological relevance of ethnographic details, in order to create a context to relate Trinidad and New Guinea. This chapter is, in many respects, a continuation of some of those conversations.

An uncanny event is normally viewed as something unexpected and unexplainable. Even in anthropological thought, uncanniness is a phenomenological concept that serves as a catalyst for cultural meaning but eludes cultural control. Analytically inspiring, methodologically unplanned and ethnographically untamed, uncanny events gain significance for anthropologists and their subjects because of how they bind together a culturally constituted human quest to understand the vicissitudes of the world with anthropologists' quest to understand human thought and behaviour. Throughout his work, Tuzin explored the nexus between uncanny coincidence and cultural efforts to craft significance. Informed by works such as Charles Morris's Foundations of the Theory of Signs (1938), Susanne Langer's Feeling and Form (1953) and Isaiah Berlin's essay on Giambbattista Vico (1976), Tuzin confronted the uncanny in all its ontological obscurity and cultural salience. This chapter builds on this foundation to explore how the uncanny can be socially planned and culturally crafted rather than accidental.

\section{An Uncanny Death in Trinidad}

Soon before I returned to Trinidad in 1996, Constantine died. The circumstances of his death were disturbing. He had gone hunting with his dogs and several friends and, during the hunt, he became separated from his partners. When it was time to return home, he could not be found. The next day the hunters returned to look for him, and they found his body in a place where they thought they had looked the day before. Constantine's body was being guarded by one of his loyal dogs in a part of the jungle associated with jumbies - the spirits of the dead. Such places are here and there in the forest where one finds indications 
that somebody had once farmed-lone cocoa trees or fruit trees or stands of non-native species of tubers. Far from any current road or habitation, these places are disconcerting. They conjure up a spectral presence of human activity where none was expected. This is not merely a recent phenomenon: in his 1884 book, Trinidad, L. A. A. de Verteuil mentions a survey of the forest conducted in 1849, approximately 40 years before the first official titles were given to any land in this part of Trinidad. De Verteuil says the surveyors found evidence of previous occupation:

These gentlemen observed, on their route, several cacao-trees: were they accidentally planted, or are they the natural growth of the country? They fell in also with brush-wood, and a few lime-trees; such being evidence that, during slavery, the maroons or fugitive slaves resorted to that spot as to a fastness. (1884:331)

Along with the occasional discovery of human bones in the forest, such places affirm that the jungle is a mysterious place with secrets. But the jungle is not a homogeneous space; only particular locations are spooky. Constantine died in one such place; his dog kept silent guard over his body in that place; and his body and dog eluded the efforts of his friends to find him for a day.

Significance was given not only to the place of Constantine's death but also to the timing. Constantine had died at a moment in his life when he was unusually embroiled in local conflicts. He had been a highly respected man. After he retired, he was still robust and full of energy. In addition to devoting himself to his land and to his hobbies, he became a leader in local politics. He was of unchallenged character, and his suggestion that there was local-level corruption garnered attention at the same time as it cultivated bitter animosities among his political foes. Only a short time before his death, political passions had reached fever pitch in a hotly contested parliamentary election that had resulted in a tie.

So Constantine had enemies. Death under such circumstances in a haunted place was a coincidence that evoked images of supernatural forces at work. As Khan (2004:109-18) has described for Trinidad, belief in such forces is part of the Trinidadian spiritual landscape, and these beliefs span the religious diversity of the island, which includes Christians, Hindus and Muslims. Obeah and 'science' - both means of manipulating supernatural forces and spiritual agents - are employed to address small and large problems and to redress major and minor offences. Obeah and science are also parts of the folklore of Trinidadian politics. Particularly powerful political leaders are associated with having supernatural powers - such as the ability of the union leader T. U. B. Butler to elude police capture during the labour riots of 1937. The leaders of Trinidad have never gone to the extent of Françoise Duvalier (Papa Doc), the Premier of Haiti from 1957 to 1971, in actually dressing to mimic the image 
of a spirit, as Duvalier adopted the dress and style of the Vodun loa Ghedethe guardian of the cemetery - but there have been moments when Trinidadian leaders have engaged in public performances with supernatural implications, such as Prime Minister A. N. R. Robinson's use of a bois while recuperating from injuries he suffered during the 1990 attempted coup d'état. A bois is ostensibly a walking stick, but it also has an association with obeah and the magic associated with stick-fighting. Robinson made no attempt to downplay this connotation that his new bois gave him magical strength, and in fact when convalescing posed for photographs with his new bois.

So the uncanniness of Constantine's death was built on a foundation of local shared knowledge about the forest and shared ideas about the supernatural. This was a death that needed to be explained in terms that transcended the religious and ethnic divisions found in Trinidad. The uncanniness of the event spurred an inter-subjective, inter-ethnic, interfaith acknowledgment of the truth of spiritual forces. At the wake, Hindus, Christians and Muslims all agreed on the strangeness of Constantine's death and displayed shared feelings, in response, that there is more to existence than the familiar.

In fact, the discussions at the wake for Constantine were quite unusual. I have attended many Trinidadian wakes, and usually discussions about the cause of death are expressed in terms of either biomedicine or humoural medicine. Even unexpected deaths are explained in these terms, such as when a seventeenyear-old died a few years before Constantine. In this case, the youth's autopsy indicated that he suffered from an aneurysm, and the discussions at the wake focused on his engaging in 'hot' activities followed by taking a cold shower in the middle of the night that caused a blood vessel in his brain to 'bust'. The uncanniness of Constantine's death was not merely that it was unexpected, and not merely that he died in a part of the forest associated with jumbies, and not merely that his body was not found for a day despite his companions' attempts to find him, but the combination of all these factors with the conflicts in which Constantine had been embroiled. The constellation of elements associated with his death pointed to forces beyond body humours and medical conditions, and, for that matter, beyond the religious differences between Hindus, Christians and Muslims.

\section{The Uncanny and Cartesian Epistemology}

In some respects, the feeling of the uncanny evoked by Constantine's death is discussed in Freud's essay 'Das Unheimliche'. Cixous describes this essay as 'a commentary on uncertainty' (1976:525), but its equivocations and elisions display signs of Freud's own uncertainty, as well. In the essay, Freud occasionally 
admits and recounts some of his own uncanny experiences and, in so doing, he generates a problem for himself. While he intellectually dismisses uncanny experiences as a problem of reality testing and repetition compulsion, his claim that superior rationality and reality testing allowed him to dismiss the uncanny becomes compromised by his admission of a certain reality to the uncanny:

We- or our primitive forefathers - once believed that these possibilities were realities, and were convinced that they actually happened. Nowadays we no longer believe in them, we have surmounted these modes of thought; but we do not feel quite sure of our new beliefs, and the old ones still exist within us ready to seize upon any conformation. As soon as something actually happens in our lives which seems to confirm the old, discarded beliefs we get a feeling of the uncanny...Conversely, anyone who has completely and finally rid himself of animistic beliefs will be insensible to this type of the uncanny...The whole thing is purely an affair of 'reality-testing,' a question of the material reality of the phenomena. (Freud 1976:639; emphasis in original)

For Freud, the uncanny creates uncertainty, and he seems unwilling to accept or believe that it has ontological implications. He assumes, a priori, that it creates an illusion grounded in the repetition of some unconscious anxiety. Yet, the phrase 'actually happens' haunts Freud enough for him emphasise it, and this phrase will continue to haunt the discussion here of the uncanny. Freud is caught in a dilemma: his idea of reality testing forces him to dismiss beliefs used to understand something that 'actually happens' and which, therefore, involve 'the material reality of the phenomena'.

Freud's dilemma emerges from his Cartesian epistemology. The uncanny often refers to events in the world that 'actually happen', but Freud can only address and eventually dismiss the interpretation of the events, not the 'material reality' of the events themselves. In the case of Constantine's death, the place and time were not psycho-dynamically determined. One could argue that there was still no need to explain his death beyond natural causes, yet what disconcerts contemporary Trinidadians about the part of the forest that gave Constantine's death its uncanny character also disconcerted de Verteuil in 1884 and surveyors in 1849. The uncanny is uncanny because, in Freud's words, some aspect of the 'material reality of the phenomena' in the world 'actually happens', and this material reality demands an explanation.

In his separation of the mental from the material world, Descartes suggests that there are different methods of study for each. Descartes claims that we know our minds better than our bodies and that the knowledge of mind is due to "natural enlightenment' (1983:6). The material world consists of 'objective reality' 
outside human thought (Descartes 1980:70-1). But in Descartes' discussion of his idea of objective reality one again finds the seeds of conundrum posed by the uncanny:

[I]f we posit that something is found in the idea that was not in its cause, then the idea would get it from nothing; but as imperfect a mode of being as this is, by which a thing exists in the intellect objectively through an idea, it nevertheless is surely not nothing; hence it cannot get its existence from nothing. (Descartes 1980:72)

The Cartesian dilemma seems to be that the uncanny is either a part of objective reality or it comes from nothing. Freud's solution is to attribute it to repetition compulsion; uncanniness derives from a previous objective reality being added to present perception. The problem of the anxiety about Constantine's death was not due simply to memories and cultural ideas of jumbies but to coincidence: the 'objective reality' of his death in a place with traces of long-disappeared human cultivation in purportedly virgin rainforest.

Descartes' division of knowledge led to an emphasis on observable and measurable facts in the social and physical sciences. Empirical research had to be contextualised as investigating a world of facts. As Poovey (1998) has shown, the ontological status of these facts is not as secure as many might hope. The definition of fact, she argues, has its roots in rhetoric-namely, in how information is represented as objective. She notes that the modern fact only emerged in an episteme that distinguished between observed particulars and theory so that these observed particulars could become evidence capable of supporting or disproving theories (Poovey 1998:92). Built upon Descartes' division of knowledge, matters of spirituality lie outside of the realm of observed particulars.

This creates a dilemma for the scientific study of religion as separate from theology, for it excludes the phenomenology of the spiritual from analysis on grounds that it is not observable evidence. Based on Descartes' famous statement 'I think, therefore I am' (1983:5), it also separates the study of matter from the issue of ontology; the ' $\mathrm{I} \mathrm{am}^{\prime}$ ' is a consequence of 'I think', and thought has an ontological status superior to that of the material world that would exist even if the body did not (Descartes 1980:18). In fact, the existence of the material world is simply taken for granted: 'that there really is a world, that men have bodies, and other such things, concerning which no one of sound mind has ever seriously doubted' (Descartes 1980:54).

In this dualism, the uncanny is disruptive. The coincidences on which the sense of the uncanny are founded are observable particulars, but these coincidences serve as an indicator of mystical connections beyond observation. In this way, it 
is similar to Otto's exploration of mysterium - one component of his discussion of the idea of the holy. Mysterium involves a sense of something 'hidden and esoteric, that which is beyond conception or understanding, extraordinary and unfamiliar' (Otto 1950:13). But the ease with which the experience of mysterium can lead to the idea of the holy suggests a bridge across the Cartesian divide, and, as a post-Cartesian troll, Freud does not want that bridge crossed. Part of the Cartesian dilemma posed by the uncanny, then, is that it involves something that 'actually happens', which evokes mysterium.

The Cartesian dualism thus places Freud in an uncomfortable if not untenable position. In response to the uncanny, Freud suppresses it in favour of a nonspiritual, observable reality as determined by his preconceived notion that reality testing only includes observable particulars and therefore must exclude the spiritual.

Donald Tuzin had no such problem. Tuzin invoked Vico's critique of Descartes' dualism as a means to avoid being impaled on the horns of the Cartesian dilemma of choosing between the spiritual and the material. He was particularly enamoured of Isaiah Berlin's discussion of Vico in Vico and Herder. Berlin (1976:25) represents Vico's view on Cartesian dualism as: 'Descartes is the great deceiver, whose emphasis on knowledge of the external world as the paradigm of all knowledge has set philosophy on a false path.' In contrast, Vico developed a distinction between verum and certum - truth and certainty. His idea of truth was that it was created by the human mind; according to Berlin (1976:13-14), only 'where we make or design something out of literally nothing, can we be said fully to understand what we have made; for in that situation to create, and to know what and why we are creating, is a single act. This is how God creates.' Certum, on the other hand, refers to the human mind's relationship to the physical world. In this relationship, the world is perceived, not directly constructed. This gives natural scientific knowledge of the world an epistemological status different from that of truth. In contrast, the study of human efforts at creation - the study of history for Vico and the study of culture for Tuzin - allows a window into verum. As Berlin put it: 'In history we are the actors; in the natural sciences mere spectators' (1976:67).

The concept of verum - the creation of truth - is an important dimension of Tuzin's study of the Tambaran cult of the Ilahita Arapesh. Tuzin was not a simple Vichean, however. He coupled truth with illusion: truth 'cannot even be known to exist - except through the medium of illusion' (1995:298). Tuzin's idea of illusion in religion is better thought of as the magician's creation of experience to generate wonder rather than as Freud's (1961) cynical emphasis on delusion in his The Future of An Illusion. Tuzin emphasises the aesthetic of 
the magician's creation of illusion, including the awareness of the Arapesh men that they are the ones engaged in the creation of the illusion and that secrecy is necessary to pull it off.

Tuzin coupled Vichean dualism with Suzanne Langer's (1953) approach to aesthetics and Charles Morris's (1938) pragmatism. One of his favourite quotes was from Langer's Feeling and Form: 'But the status of the unfelt feelings that inhere in art objects is ontologically obscure' (Langer 1953:22). Langer's emphasis on the ontological obscurity of the unfelt feelings in art fits well with Morris's pragmatic dimension of meaning. As Tuzin put it, the symbol 'is apperceived to have intrinsic import' (1977:197). The apperception is at once both an individual process and a collective endeavour. The object of religious art, such as the Tambaran spirit house, is an object in the world, but the powerful feelings attached to the object are less ontologically clear; are they in the object or in the mind? Tuzin adopts a Vichean response to this question; the focus on apperception rather than perception indicates an active process in the creation of meaning rather than a passive process in the perception of meaning.

The active process in the creation of meaning involves not simply reaction to objects but also the creation of objects - one of Langer's crucial insights. In a statement of Langer's contribution to his thought, Tuzin wrote that works of art 'are not expressive of actual, untransformed emotion, but rather they express the idea of emotion' (1977:198). For Tuzin, the idea of emotion in the art spurs a cultural response through social processes; for Tuzin, who was trained in the British social anthropological tradition, this was a Durkheimian rather than cultural-constructivist perspective. For instance, the paintings associated with Nggwal, the spirits of the highest initiation level in the Tambaran cult, are an important meeting place of collective religious sentiment and individual expression. The Nggwal involves 43 named spirits in which 'each individual's relationship with his nggwal is personified in a painting' (1980:175). These paintings are then displayed in the outer sanctum of the spirit house on the wall that divides the inner and outer sanctums. Tuzin says of this display:

By its design the gallery wall elevates the symbolic office of these paintings to a higher level. Here, in graphic rendition of the conceptual realm, the individual spirit is socially ennobled by virtue of its placement in a mosaic which orders while pictorializing the collective spirituality of the village. In the logic of the Tambaran, therefore, the men are quite correct when they proudly proclaim that Nggwal-the image par excellence of the village collectivity-dwells in his house. Had the scheme been designed by Durkheim himself, it could not have expressed better the mirror which religious ideology holds up to the social order. (1980:180) 
Tuzin's Durkheimian twist on the combination of Langer's and Morris's approaches to symbols removes the interpretation of symbols from the strictly Freudian realm of the connection of the symbol to the individual unconscious and instead places the interpretation of symbols into the nexus of individual and collective experience and emotion.

This raises a contrast between Freud's post-Enlightenment intellectualism and Tuzin's approach to Arapesh religion; in the former, the uncanny is disruptive and in the latter, it is catalytic. Yet, Freud's suppression is not the only form of post-Enlightenment response to the uncanny. The colonial encounter created another form of suppression: the uncanny could be dismissed as the naive superstition associated with the colonised or uneducated masses. In the Caribbean, the uncanny is a prevalent component of representations of the West Indies, whether it be zombis associated with Haitian Vodun, obeah or spirit possession. Palmié (2002:216) traces how brujeria, Cuban witchcraft, came to be seen by Ortiz, a student of Malinowski, as 'an affliction, not of concrete people but of the republican mind; a hybrid formation, not just in the literal sense, but also in terms of the way in which it seemed to disfigure the identity of the clases responsables of the neocolonial republic'. The uncanny in the Caribbean is not denied, then, as Freud does, but is seemingly dismissed as attached to a deviant, counterproductive state of mind. Within a Cartesian dualism, this dismissal is made possible by transforming the uncanny into merely a state of mind. But Constantine's death still haunts this transformation, not because of a state of mind but because of the coincidence of when, where and how he disappeared and died. The feral, non-native yams and fruit trees in the forest are not a state of mind in the Cartesian framework but a component of the material world - observed particulars out of which scientific knowledge should be able to be constructed. That is what makes Constantine's death unsettling-namely, the empirically observed particulars that unsettle the analytic ability to dismiss cultural efforts at interpretation. Even within the colonial logic, as with Freud, labelling the interpretations as irrational or deviant only dismisses them, not what 'actually happens'.

Even before Tuzin explicitly invoked Vico in his work, he expressed concern about Cartesian dualism and anthropological concepts. His first book, The Ilahita Arapesh: Dimensions of Unity, concluded by revealing ontological uncertainty in Lévi-Strauss's theory of binary oppositions. Tuzin wrote: 'as it is usually presented the theory presupposes a Cartesian metaphysic of Mind - the absolute autonomy of "reality" as distinct from "experience" - and once this logical Rubicon is crossed, there is no further inquiry which is not either teleological or formally meaningless' (1976:329). Later, he wrote: 'we must resist an unwitting participation in the cosmology we are studying which presumes that both it and our own scientific ontology are merely different manifestations of a common 
Cartesian principle' (1976:334). The surprising conclusion of Dimensions of Unity implies that Cartesian epistemologies possibly pose a challenge to empirically grounded ethnographic research. The implication is that theoretical constructs that assume distinctions of mental and observable phenomena are ontologically dubious. It is difficult to tell whether they emerge out of observed particulars or whether they are preconceived categories imposed on observed particulars. What, after all, is the ontological status of social structure, or culture? Or, if the readers of a volume otherwise dominated by Melanesian studies will indulge me, what is the ontological status of the concepts of creolisation and hybridity that dominate current discussions of the post-colonial Caribbean?

As descriptive labels, creolisation or hybridity seem to lend themselves to an analysis of the discourses of local politics and jumbies evoked by Constantine's death. In the hands of Caribbeanists, these ideas are constantly deployed to discuss the nexus of political action and significance with spiritual dimensions that seem to have an African or South Asian origin. In Trinidad, the connection between jumbies and political strife can be explained by reference to Trinidadian's long experience of colonially created ethnic divisions and postcolonially cultivated rancorous politics. There is a rhythm to these tensions such that they are heightened during and immediately following parliamentary elections, which must occur no later than every five years. Constantine was embroiled enough in political debates and died close enough to parliamentary elections that the coincidence was an important component of conversations to make sense of his death. Jumbies are viewed as specteres whose powers can be harnessed through the practice of obeah. Hence, it makes sense that being in a place associated with jumbies when one has enemies would be potentially dangerous. Creoliszation and hybridity focus on dynamic processes that produce this mix, but the mix, like the uncanny, often bridges the Cartesian divide.

There is a problem, however, with perspectives such as creolisation and hybridity. One might label an explanation of Constantine's death as a form of hybridity or as a consequence of creolisation, but this, in fact, bypasses the problem that nags Freud. Hybridity and creolisation are concepts that refer to the consequences of contact between different peoples, but the place and time of Constantine's death are not determined by such contact. His death might evoke a creolised response, but it was not creolisation in the conventional sense of the term that brought about Constantine's death in a stand of feral cultigens. There are events that 'actually happen' that seem outside the purview of these concepts from post-colonial studies, and this limit on these concepts is not confined to singular events such as Constantine's death. In response to these events that actually happen, creolisation and hybridity merely serve as labels after the fact, not really as a means of explaining what has happened. 
Within anthropology, the challenge of addressing what 'actually happens' is an important part of the longstanding tradition within the field of disrupting Western epistemological complacency, such as Evans-Pritchard's representation of his discussion with Azande about the collapse of an old granary. 'That it should collapse is easily intelligible, but why should it have collapsed at the particular moment when these particular people were sitting beneath it?' (Evans-Pritchard 1937:69). Evans-Pritchard admits: 'We have no explanation of why the two chains of causation intersected at certain time and in a certain place, for there is no interdependence between them. Zande philosophy can supply the missing link' (p. 70).

\section{The Planned Uncanny}

While the uncanny might refer to anomalies, it does not include only the accidental and unexpected. This is implied by Freud's use of a work of fiction, Hoffman's The Sand-Man. If, as Nietzsche argues in The Birth of Tragedy and the Genealogy of Morals (1956), the plot of tragedy is known, and this knowledge gives its affective import to the audience, the use of a work of fiction to demonstrate and explore the uncanny suggests the possibility that the uncanny is expected. Freud equivocates on this when he writes: 'in the first place a great deal that is not uncanny in fiction would be so if it happened in real life; and in the second place... there are many more means of creating uncanny effects in fiction than there are in real life' (1976:640, emphasis in original). This equivocation is itself based on Freud's Cartesian distinction between 'reality' and 'fiction', but, from Tuzin's point of view, this boundary is not as clear as Freud wishes. Tuzin argues that the uncanny can be created through ritual practice. The sound created by the bullroarer is one such case. In his article 'Miraculous Voices', he argues that

a certain type of naturally occurring sound has a perceptual effect on some, possibly many, animal species that is intrinsically mysterious and thus anxiety arousing; that this sensation is humanly interpreted and its accompanying anxiety cognitively resolved by referring it to the mystery that is allegedly inherent in the supernatural realm; and that certain kinds of ritual sounds capitalize on this iconic resemblance by simultaneously mimicking, as it were, factual and artifactual mystery, thereby summoning the senses to bear witness to the noetic truth of the sound's religious meaning. (Tuzin 1984:579)

In his discussion of the association of the bullroarer with Lefin, the Tambaran cult's second age grade and the name of a Tambaran spirit, Tuzin emphasises that 'the active aspect of Tambaran power, to the extent it can be known, is conceived by men to reside in its voice' (1980:57, emphasis in original). This 
voice is manifested by the bullroarer. When played, this instrument creates the sound of Lefin, a 'big-mouthed, red-haired dwarf' (Tuzin 1980:60), crying 'I am a great, great man; I am a great, great man' (Tuzin 1984:582).

Tuzin states that the sounds produced by the bullroarers 'are the cult spirits represented in their voices' (1984:582). He argues that the volume and tone of the bullroarer not only are heard but are felt; they create infrasonic waves. Consequently, the experience of the sound of Lefin is perceived not only through normal auditory perceptual paths but is felt through non-auditory paths as well (Tuzin 1984:586), thereby fostering a sonic experience and consequent mental state that evoke 'sensations of the uncanny, the dreadedly obscure' (p. 587). In effect, the sense of mysterium Otto described and which is crucial to the uncanny can be created and reproduced. It can be deployed to give significance to moments of time.

In this sense, the creation or reproduction of a sense of mysterium can be related to Benjamin's (1969) idea of messianic time - the uncanny disrupts homogeneous empty time through the demand that the uncanny be given meaning. As Robbins (this volume) states, messianic time connects 'potential emancipation' with events in the present. But I want to maintain a distinction between messianic time and uncanny disruptions to homogeneous empty time. Uncanny coincidences provoke the creation of meaning that makes a moment unique and significant, but they need not convey any messianic hope.

What messianic and uncanny forms of temporal disruption share is the copresence of a sense of existence beyond the lived moment with the mundane sequences of life. Such co-presence is at the heart of Augustine's discussion of memory and time in his Confessions, where he argues that the tension between time and change and God's unchanging eternity is what gives time meaning (1997:266-72; see also Ricoeur 1984:5-30). One can also view these uncanny times as moments when, as Hauser-Schäublin (this volume) discusses, there is a co-presence of the transcendental with the lived moment. Put into a rubric of time that echoes Augustine's discussion of time and eternity, such co-presence can be a moment when a sense of eternal or transcendent time intersects with the sequences of lived existence.

In Hauser-Schäublin's chapter in this volume, one gets a sense of how a logic of concealing and revealing in the rituals of initiation into grades of the Tambaran cultivates such a co-presence. As Tuzin's The Voice of the Tambaran showed, staging these rituals is not an easy or trivial matter, but involves immense preparation; the sense of mystery evoked in these rituals through the play of revealing and concealing is therefore anticipated and planned. The uncanny disruption of homogeneous empty time can be a staged and planned event. 
In Trinidad, the seasonal timing of ritual observances of different religious traditions is a source of the uncanny because of the coincidences created by the intersections of Christian and Hindu calendars. The cycles of holidays in calendars from different religious traditions intersect to create moments of significance. As in Constantine's death, the coincidences are what foster the sense of the uncanny - of a beyond that is not fully known yet actually there. Every year, the Hindu celebration of Divali nearly coincides with the Roman Catholic celebrations of All Saints' Night and All Souls' Night. Divali involves lighting deyas — small clay lamps with a cotton wick; All Saints' Night involves lighting candles outside the home; and All Souls' Night involves lighting candles on the graves of loved ones. During my first All Souls' Night in Trinidad, standing in the cemetery among a crowd of Muslims, Hindus and Catholics seeking the graves of their deceased loved ones in order to light candles, many of my neighbours impressed upon me the parallels between Divali and All Saints'; to them, both represented the victory of light over darkness. Divali, in fact, is thought to occur on the darkest night of the year - a new moon after the autumnal equinox. How might the coincidence of such different religious traditions be explained? The Trinidadian cultural response is to engage in a form of creolised ecumenical theology - that the similarities between religious events reveal a deeper truth than any of the religions individually.

This local-level, theological explanation emerges from the contact between different groups exploring the similarity in timing of some of their religious practices - their effort to create a collective truth. The local explanation is an example of hybridity and creolisation, but the materiality of the uncanny - the component that 'actually happens' - indicates something beyond a coincidence of religious practice. The way in which these calendars interact is a catalyst for creolised interpretations but is not caused by creolisation; colonialism brought into contact pre-existing calendars from different parts of the world but did not create the calendars. In fact, it is the perception of an independent origin of these two calendars that makes their coincidence seem uncanny.

At least in Hinduism, if one moves from religious practice to the justification of the practice, one is confronted with an ethno-astronomical explanation. Divali is associated with an event in the night-time sky. Hinduism is fixed on the skies in ways that contemporary Christianity is no longer. Hinduism, in particular, emphasises the coincidence of celestial bodies as crucial to understanding one's fate and making wise decisions. The Hindu claim that Divali falls on the darkest night of the year is not merely a cultural claim but an ethno-astronomical one based on the decrease in sunlight after the autumnal equinox and a new (or dark) moon after what, in the West, is known as the Harvest Moon - the full moon nearest to the autumnal equinox that is reputed to be brighter than other full moons. 
It is possible to step out of the context of creolisation in Trinidad and enter into a broad play of the uncanny coincidence of the recognition of autumnal celestial darkness, since the American celebration of Halloween also coincides with this darkest time of the year, as does the Mexican Day of the Dead (which coincides with All Saints' Day and All Souls' Day).

Such ethno-astronomical awareness was once part of Christianity, gave significance to some holidays and determined the dates of other commemorations. For instance, in an essay attributed to Anatolius of Laodicea in the third century, the timing of Easter was described in terms of ethno-astronomical significance:

[A]s long as equality between light and darkness endures, and is not diminished by the light, it is shown that the Paschal festival is not to be celebrated. Accordingly, it is enjoined that that festival be kept after the equinox, because the moon of the fourteenth, if before the equinox or at the equinox, does not fill the whole night. (Anatolius 1926:149)

In 1733, Isaac Newton also suggested a tie between astronomy and religious commemoration in Christianity:

They who began first to celebrate [Christian holidays], placed them in the cardinal periods of the year; as the annunciation of the Virgin Mary, on the 25th of March, which when Julius Caesar corrected the Calendar was the vernal Equinox; the feast of John Baptist on the 24th of June, which was the summer Solstice; the feast of St. Michael on September 29, which was the autumnal Equinox; and the birth of Christ on the winter Solstice, Decemb. 25. (Newton 1998:143)

But ethno-astronomy goes only so far as a form of explanation. Easter is tied to Passover, and Passover is determined by astronomical events. Why is it that these events coincidentally occurred around the spring equinox when light is ascending? Again, the full moon coinciding with the vernal equinox is a coincidence observable in the material world.

The juxtaposition of discussions of the resonances between Hinduism and Catholicism in Trinidad and with de-contextualised examples about the sacred dimensions of celestial events from Anatolius and Newton is meant to stir a sense of uncanny similarity between societies that are not directly connected. This, too, was something that Tuzin explored, in his work with Gregor comparing Amazonia and Melanesia (Gregor and Tuzin 2001). The uncanny resemblances seem to point to elements of psychic unity and, in the case of the impressive sound of bullroarers and the coincidence of autumnal holidays, disparate cultures that note repeatable, widespread phenomena that 'actually happen' but which generate a sense of mysterium. Tuzin's willingness to broach these issues in a spirit of scepticism and openness in fact revives the possibilities of 
broad-based comparisons of cultures. In Tuzin's approach, this is not to place them in broad classifications but to understand components of the human cultural creative process. The origins of the bullroarer are shrouded by time, and whether its presence in Melanesia and Amazonia is the result of diffusion or independent invention was of little interest to Tuzin. What was of interest was how the bullroarer created similar experiences in Melanesians, Amazonians and ethnographers, and the fact that the similarity of experience prompted cultural interpretation. There is also the recognition that societies differ in whether they cultivate planned experiences of the uncanny, and the question of how societies accomplish this. In fact, even though it is obvious, it bears to be stated: a coincidence between the practices of two societies does not mean that there must be a coincidence between the practices of all societies for a sense of the uncanny to emerge. After all, Islam does not have a commemoration that regularly corresponds with Divali or All Saints'/All Souls' because the Islamic calendar is strictly lunar. It therefore has a year that is 11 days shorter than the solar Gregorian calendar and never readjusts the lunar to the solar year through an embolismic month, as does the Hindu calendar. Yet, even though Islam is not part of the uncanny coincidence of Catholicism and Hinduism in Trinidad - at least in my field site-Muslims appear at the cemetery on All Souls' Night to light candles and join in the discussion of how all religions celebrate the victory of light over darkness.

Still, the existence of coincidences between cultural practices and the practice in many societies of cultivating uncanny experiences allowed Tuzin to plumb the depths of common ways to stir the human spirit while leaving open how such stirring is culturally employed and interpreted.

Ritual, then, can involve not only the creation of truth in response to the uncanny, but also the creation of the uncanny by reference to features of the environment that 'actually happen'. The sonic qualities of Arapesh ritual are not accidental, and the coincidence of sound and ritual action is planned and practised rather than unexpected or unpredictable. Likewise, the coincidence of Divali and All Saints' is part of the annual cycle of holidays. The uncanniness derives from the coincidence of two holidays from two different religions representing very different cultural traditions within Trinidad. Examples of an expected uncanny experience do not diminish its effect; the uncanny qualities of the sound still create a numinous experience in Arapesh ritual, and the uncanny coincidence of holidays still spurs theological musings. 


\section{The Uncanny and Anomie}

Just as the uncanny can be created in order to stir the spirit and create truth, Tuzin provides an account of the uncanny being denied. The Cassowary's Revenge explores an idea that is complementary to Vico's wisdom: the criterion of the false is to have unmade the true. The dismantling of the Tambaran made it false, but in The Cassowary's Revenge there remains scepticism about the falsehood of the Tambaran. In this ethnographic description, scepticism ceases to be opposed to religion but is opposed to any system of truth/falsehood; and the persuasiveness of truth and falsehood is against the ground of scepticism but, under the new circumstances, the uncanny does not lead to collective conscience but to anomie - a move from Durkheim's The Elementary Forms of the Religious Life (1995) to Suicide (1979) as a source for insight. In fact, Tuzin laments this in the last chapter of the book, where he discusses the possible functions of men's cults. Maybe there are here clues to understanding the disruptiveness of the uncanny for modernity. In an ontological system that dismantles collective responses to ontological uncertainty in favour of individualised ontological doubt, the uncanny has little power to mobilise.

In the case of post-Tambaran Ilahita, this disruption had not led to the reestablishment of a collective consciousness, although it seems that millenarianism has had this outcome in other parts of Melanesia (see Robbins, this volume). In this regard, the inability to fully resuscitate ontological obscurity in the face of socially sanctioned doubt created anomie. Augmenting Durkheim, Tuzin's approach to anomie merges the problem of social isolation with a phenomenological experience of anxiety about reality. In one way, this parallels Heidegger's (1962) treatment of the uncanny as a primordial experience of the world and the individualised disruptiveness of the uncanny, but Tuzin does not agree with Heidegger's claim that the uncanny is always an individualised experience. Instead, he seems to imply that the individualisation of the uncanny is a consequence of social disintegration. The public face of the uncanny had no concealed dimension of socially sanctioned secrecy. When it is assumed that everything known is revealed then the uncanny is unsettling. The possibility of a reservoir of ontological obscurity allows for the creation and cultivation of secrets that can be deployed socially. The disclosure of the Tambaran cult's secrets did not dispose of ontological obscurity, only this reservoir of secrecy with which the obscurity could be handled.

Tuzin's The Cassowary's Revenge suggests that, in the wake of the revelation of the Tambaran cult's secrets, the uncanny is not denied, but there is no cultural structure remaining that can adequately address it. As Palmié (2002) suggests for the Caribbean, the uncanny is more often disavowed than denied. It is much more like the situation that Ewing (1997:163) describes in Pakistan, 
where ' $[\mathrm{m}]$ any highly educated Pakistanis who regard themselves as modern, rational, and professional are...caught between ideologies, inconsistent in their self-representations, uncertain about how to articulate their relationships to Islam and to modernity. Many are drawn to Sufism and yet avoid identifying themselves as Sufis.' The congruence of Melanesia, South Asia and the Caribbean suggests a condition of the post-colonial world. In effect, in the post-colonial context, the uncanny reveals the incompleteness of European Enlightenment hegemony about being and knowing. Concepts such as culture, social structure, hybridity and creolisation serve to deflect attention from the uncanny that 'actually happens'. The emphasis is shifted from the uncanny event to the interpretation of the event. In effect, uncanniness is split into the materiality of what actually happens and interpretation of what actually happens, with the materiality ultimately being neglected or dismissed.

The ontological obscurity of the spirits in art, ritual and uncanny events makes Tuzin's work an unusual intervention in understandings of the role of the uncanny in anthropology with implications for understanding fissures in postcolonialism and modernity. The tacit adoption of Descartes' epistemological dualism has led anthropology either to dismiss the uncanny or to assume the uncanny and its accompanying ontological anxieties are a disruptive force, but Tuzin's ethnographic discussions lead him to view it as a socially creative force. Rather than dismiss or disavow the uncanny, his synthesis of Vico and Langer allows him to embrace the ontological uncertainty it creates and the culturally creative consequences of this uncertainty based on events that 'actually happen', which stir the spirit. Cartesian dualism has led to a social scientific fear of having the spirit stirred in response to what actually happens. Tuzin had no such fear.

By adopting a Vichean dualism, Tuzin allowed his spirit to be stirred without necessarily going down the road to religious faith. He emphasised and celebrated scepticism, but his Vichean approach to the uncanny allowed his scepticism free rein to include both religion and claims of rationality. Repeatedly, Tuzin describes how scepticism about the existence of spirits and sorcery lays the foundation for the extraordinary collective experience of spirits and sorcery in ritual or in response to unexpected events or strange coincidences; the stirred spirit is all the more remarkable when it emerges out of scepticism. For instance, he describes one informant who intimated that just as the fiction of a physical Nggwal enables men to dominate women, so the fiction of an invisible Nggwal enables the senior initiates to dominate their junior colleagues. The lie is itself a lie' (Tuzin 1980:212). Tuzin remarked on the resemblance of this statement to certain forms of atheism and existentialism; 'belief in self replaces belief in Nggwal; the human actor assumes the godlike functions of Nggwal' (1980:213). But then, a few days later, this informant had a dream in which he was chased by 
animated Nggwal statues, and this dream changed his imagination of Nggwal: 'No longer the free-wheeling agnostic, he had reverted to an anxious literalism that verged on the abject credulity which, in happier moments, he scornfully ascribed to women' (1980:214).

Tuzin's attention to sensory perception - the sights of the spirit house, the terror evoked by the din of bullroarers, the exquisite pain of ritualised penile bloodletting - adds a phenomenological dimension to his link between the ontology of spirits and the imagination of community. Rather than being disruptive of society, the counterpoint of uncanny events, sensory experience and scepticism becomes the foundation for Durkheimian social connections.

In Tuzin's work, then, the uncanny is consistently portrayed as a productive, creative force. It is creative in how it prompts the collective imagination and creation of truth, and this catalyst of the imagination plays an important role in religious experience and, in an interesting, parallel fashion, in anthropological methodology. In both cases, the uncanny is something that requires attentionsignifying a moment of potential insight through its unsettling of ontological complacency.

Returning to the Caribbean vignettes I have offered, Constantine's death and the congruence of Divali and All Saints' are uncanny events that, according to Tuzin's logic, must either produce a social response at creating an illusion of truth or create individualised anomie. This allows some insight into the Vichean problems of post-colonial studies. The social divisions created by colonialism and its enlightenment heritage seem to highlight the opposed Durkheimian paths to collective conscience or to anomie. For instance, M. G. Smith's (1965) model of cultural pluralism seems to suggest social disintegration except for the power of the state. This was a model that Tuzin learned quite well at the hands of his undergraduate anthropology professor, Leo Despres, a specialist in the study of Guyana who was an advocate of Smith's cultural pluralism theory. Tuzin's familiarity with this model seemed to breed contempt for it; he was utterly unconvinced by the anomic representation of such societies. He was more sympathetic towards creolisation, but still regarded it as a grand term that probably obfuscated a diversity of practices and ignored points of tension and fissure in Caribbean societies. I do not think he would have been much more satisfied with hybridity - a label that is often confused with being an explanation. From a Cartesian perspective, all of these are models attempting to label observed particulars. From Tuzin's Vichean perspective, they are acts of anthropological creation. Cultural pluralism, creolisation and hybridity are all models that explain what they themselves create, and in the Caribbean this is highlighted by the prevalence of scholars who are also policy makers and advisors. Such scholar-politicians use social scientific theory in their policies and strategies. In Trinidad, they approach policy making as if cultural pluralism 
were truth, and in creating institutional structures that treat the social world in terms of cultural pluralism, they make cultural pluralism true. Behind the imposing pluralist, creolised or hybridised masks are mere humans.

\section{Conclusion}

The social creation of truth to understand the uncanny is, from Tuzin's Durkheimian perspective, a cultural and social process; through the human spirits stirred to create a shared vision about the world, there is a creation of social connection. In the process, Tuzin's insights make the ontological status of all our theoretical constructs uncertain. They, too, are creations of human action rather than objects in the world to be studied, and what is of greatest importance ethnographically is to study the process of creation not the reification of categories for purposes of objective and objectifying analysis.

This leads to a significant ontological and epistemological implication of Tuzin's work. From his Vichean perspective, human action is the act of creation, and the act of creation establishes truth. The ethnographic enterprise, then, must attend to the act of creation, and the ability to create is a common human bond between ethnographers and their subjects. If attention is given to the act of creation then ethnographers can gain special insight into cultural and social processes that approach verum and maybe gain insight into acts of creating new social systems. But if attention is given to the study of ossified categories that anthropology creates to filter and shape the world the ethnographer studies then, at best, one can achieve only a form of certum that is a pale imitation of that in the natural sciences and, by privileging the pre-ethnographic conceptual creations over what actually happens, develop a Cartesian blindness to the uncanny. In mentoring me to study the Caribbean, Don Tuzin encouraged me to observe and even participate in creation; that seemed to stir his spirit in our discussions to allow us to transcend the distance between Ilahita and Trinidad.

\section{Acknowledgments}

I would like to thank Alex Bolyanatz, John Collins, Ted Sammons, and two anonymous reviewers for their comments on earlier versions of this chapter. 


\section{References}

Anatolius 1926. The Paschal Canon. In A. Cleveland Coxe (ed.) Ante-Nicene Fathers. Volume 6, pp. 146-51. Grand Rapids, Mich.: Christian Literature Publishing Company.

Augustine 1997. The Confessions. New York: Vintage.

Benjamin, Walter 1968. Theses on the Philosophy of History. In Hannah Arendt (ed.) Illuminations, pp. 253-64. New York: Schocken.

Berlin, Isaiah 1976. Vico and Herder. New York: Viking.

Cixous, Hélène 1976. Fiction and its Phantoms. New Literary History 7:525-48.

Descartes, René 1980. Discourse on Method and Meditations on First Philosophy. Indianapolis, Ind.: Hackett.

Descartes, René 1983. Principles of Philosophy. Dordrecht: Kluwer.

de Verteuil, Louis A. A. 1884. Trinidad: Its Geography, Natural Resources, Administration, Present Condition, and Prospects. London: Cassell.

Durkheim, Emile 1979. Suicide: A Study in Sociology. New York: Free Press.

Durkheim, Emile 1995. The Elementary Forms of the Religious Life. New York: Oxford University Press.

Evans-Pritchard, E. E. 1937. Witchcraft, Oracles and Magic Among the Azande. Oxford: Clarendon.

Ewing, Katherine 1997. Arguing Sainthood. Durham, NC: Duke University Press.

Freud, Sigmund 1961. The Future of An Illusion. New York: Norton.

Freud, Sigmund 1976. The 'Uncanny'. New Literary History 7:619-45.

Gregor, Thomas A. and Donald Tuzin 2001. Gender in Amazonia and Melanesia. Berkeley: University of California Press.

Heidegger, Martin 1962. Being and Time. New York: Harper.

Khan, Aisha 2004. Callaloo Nation: Metaphors of Race and Religious Identity Among South Asians in Trinidad. Durham, NC: Duke University Press.

Langer, Susanne 1953. Feeling and Form: A Theory of Art. New York: Scribner.

Morris, Charles 1938. Foundations of the Theory of Signs. Chicago: University of Chicago Press. 
Newton, Isaac 1998 [1773]. The Prophecies of Daniel and the Apocalypse. Hyderabad, India: Printland Publishers.

Nietzche, Friedrich 1956. The Birth of Tragedy and the Genealogy of Morals. New York: Doubleday.

Otto, Rudolf 1950. The Idea of the Holy: An Inquiry into the Non-Rational Factor in the Idea of the Divine and its Relation to the Rational. Oxford: Oxford University Press.

Palmié, Stephan 2002. Wizards and Scientists: Explorations in Afro-Cuban Modernity and Tradition. Durham, NC: Duke University Press.

Poovey, Mary 1998. A History of the Modern Fact. Chicago: University of Chicago Press.

Ricoeur, Paul 1984. Time and Narrative. Volume 1. Chicago: University of Chicago Press.

Smith, M. G. 1965. The Plural Society in the West Indies. Berkeley: University of California Press.

Tuzin, Donald F. 1976. The Ilahita Arapesh: Dimensions of Unity. Berkeley: University of California Press.

Tuzin, Donald F. 1977. Reflections of Being in Arapesh Water Symbolism. Ethos 5:195-223.

Tuzin, Donald F. 1980. The Voice of the Tambaran: Truth and Illusion in Ilahita Arapesh Religion. Berkeley: University of California Press.

Tuzin, Donald F. 1984. Miraculous Voices: The Auditory Experience of Numinous Objects. Current Anthropology 25:579-89, 593-6.

Tuzin, Donald F. 1995. Art and the Procreative Illusion in the Sepik: Comparing the Abelam and the Arapesh. Oceania 65:289-303.

Tuzin, Donald F. 1997. The Cassowary's Revenge: The Life and Death of Masculinity in a New Guinea Society. Chicago: University of Chicago Press. 